\title{
Praktik Akad Pembiayaan Gadai Emas Perspektif Hukum Islam
}

\begin{abstract}
ABSTRAK
Penelitian ini bertujuan untuk : 1) Mengetahui lebih medalam tentang praktik pembiayaan gadai emas di BMT-UGT Sidogiri Kantor Cabang Pembantu Kwanyar Bangkalan. 2) mengetahu akad prarktik pembiayaangadai emas di BMT-UGT Sidogiri Kantor Cabang Pembantu Kwanyar Bangkalan menurut hUkum Islam. Analisi data yang diperoleh dari penelitian adalah dapat diuangkapkan bahwa : 1) Pada dasarnya gadai emas pada BMT-UGT Sidogiri Kantor Cabang Pembantu Kwanyar Bangkalan sudah terpenuhi rukun dan syaratnya menurut fiqih muamalah. 2) Perbankan syariah yang seharusnya menyesuaikan diri dengan perinsip-prinsip syari'ah, dalam BMT-UGT Sidogiri Kantor Cabang Pembantu Kwanyar Bangkalan masih lemah dalam hal itu sehingga dapat menyebabkan tidak sahnya akad. 3) Dalam aka ijarah; penentuan baiaya administrasi, baiaya sewa tempat, dan taksiran barang BMTUGT Sidogiri masih kurang mengedepankan perisip an-taradhin atara kedua belah pihak sehingga masih dinilai sebagai keputusan sepihak dan belum sesuai dengan ketentuan hokum islam yang tertera dalam firman Allah SWT Q.S alBaqarah 2:275,278-280, dan Q.S an-Nisa' 4:29.
\end{abstract}

Kata Kunci : Gadai Emas, Akad Pembiayaan,

\begin{abstract}
This study aims to: 1) Know more about the practice of gold pawn financing at BMT-UGT Sidogiri Kwalanar Bangkalan Branch Office. 2) to know the contract of the golden installment of the gold mortgage at BMT-UGT Sidogiri Kwanyar Bangkalan Sub-Branch Office according to the Islamic Law. Analysis of the data obtained from the research is that it can be stated that: 1) Basically gold pawning on BMT-UGT Sidogiri Kwanyar Bangkalan Sub-Branch Office has fulfilled the conditions and conditions according to muamalah fiqih. 2) Islamic banks that should adjust themselves to the principles of Shari'ah, in BMT-UGT Sidogiri Kwalanar Bangkalan Sub-Branch Office is still weak in that matter so that it can cause invalid contract. 3) In the case of history; Determination of administrative costs, place rent, and estimated goods of Sidogiri BMT-UGT are still less prioritizing the participation of both parties so that they are still considered unilateral decisions and not in accordance with the provisions of Islamic law contained in the words of Allah SWT QS al-Baqarah 2 : 275,278280, and Surah an-Nisa '4:29.
\end{abstract}

Keywords: Gold Pawn, Financing Agreement,

Kholid

Dosen Ekonomi Syariah STAI Darul Hikmah Bangkalan

Kholid@darul-hikmah.com 


\section{A. Pendahuluan}

Islam merupakan agama rahmatan lil 'alamin, agama yang lengkap dan sempurna, yang meletakkan kaidah-kaidah dasar dan aturan dalam semua sisi kehidupan manusia, baik dalam ibadah maupun muamalah (hubungan antar makhluk), agama yang mempunyai karakteristik yang paling kuat dalam fungsi sistem, dan penataan. Obyek dari sistem itu adalah seluruh aspek kehidupan manusia, tidak satupun masalah atau aspek yang terkait dengan kehidupan manusia baik langsung maupun tidak langsung, melainkan Islam telah memberikan penjelasan tertentu tentang masalah dan aspek tersebut. Oleh karenanya sebagai ajaran yang bersifat universal, elastis dan fleksibelitas ajaran Islam sangat dibutuhkan dalam setiap perkembangan dan perubahan sosial dengan tanpa meninggalkan normanorma yang telah digariskan oleh ajaran Islam melalui Al-Qur'an dan sunnah Nabi.

Setiap orang membutuhkan interaksi dengan orang lain untuk saling melengkapi kebutuhan dan tolong menolong diantara mereka. Karena itulah, kita sangat perlu mengetahui aturan Islam dalam seluruh sisi kehidupan kita sehari-hari, diantaranya tentang interaksi sosial dengan sesama manusia (hablu mina al-naas) khususnya berkenaan dengan perpindahan harta dari satu tangan ke tangan yang lain.

Utang piutang terkadang tidak dapat dihindari padahal banyak muncul fenomena ketidakpercayaan diantara manusia khususnya di zaman modern ini, sehingga orang terdesak untuk meminta jaminan benda atau barang berharga dalam meminjamkan hartanya. Realita yang ada tidak dapat dipungkiri suburnya usaha-usaha pegadaian. Ironisnya, banyak kaum muslim yang belum mengenal prinsip syari'ah yang mengatur secara indah dan adil dalam Islam mengenai hal ini. Padahal perkara ini bukanlah perkara yang baru dalam kehidupan mereka, sudah sejak lama mereka mengenal jenis transaksi seperti ini.

Transaksi yang disertai dengan jaminan seperti tersebut diatas dinamakan gadai yaitu, menahan harta salah satu milik si peminjam sebagai 


\section{Praktif Akad Pembiayan Gadai Emas}

jaminan atas pinjaman yang diterimanya. Secara sederhana dapat dijelaskan bahwa rahn adalah semacam jaminan utang atau gadai

Transaksi gadai di Indonesia pada mulanya dijalankan oleh Perum Pegadaian (konvensional) dan identik dengan kalangan ekonomi menengah kebawah. Namun pada saat ini lembaga keuangan berkembang pesat bahkan hadir pula lembaga keuangan yang berbasis syari'ah dan istilah "pegadaian identik dengan kalangan ekonomi menengah kebawah" seakan hilang dengan sendirinya seiring besarnya permintaan warga masyarakat terhadap jasa Perum Pegadaian. Hal ini membuat lembaga-lembaga keuangan syari'ah seperti perbankan syari'ah juga melirik kepada sektor pegadaian dengan menghadirkan produk gadai emas yang dikemas lebih menarik sehingga dapat terjangkau bagi semua kalangan masyarakat, tidak hanya sebagai sarana utang piutang tapi sebagai sarana investasi. Dan dalam diskursus ekonomi Islam, gadai juga merupakan salah satu praktik transaksi sosial dan keuangan yang pernah dipraktekkan di masa Nabi Muhammad saw. yang amat menjanjikan mengayomi rakyat untuk dikembangkan.

Pada BMT-UGT Sidogri Kantor Cabang Pembantu Kwanyar Bangkalan yang penulis jadikan tempat meneliti produk yang menggunakan obyek emas (logam mulia) ini memiliki beberapa variant produk menarik antara lain: KLM (Kepemilikan Logam Mulia), Gadai Emas. Dalam produk KLM atau jual beli emas secara kredit yang menggunakan akad murabahah ini menawarkan kemudahan bagi nasabah untuk memiliki emas tanpa harus membayar secara tunai cukup membayar uang muka saja dengan kesepakatan kedua belah pihak dan pembayaran dilakukan secara angsuran, dalam hal ini BMT-UGT Sidogiri Cabang Pembantu Kwanyar Bangkalan bekerjasama dengan toko emas SUMBER REJEKI (Jl. Ketetang Pasar Kwanyar) Bangkalan

Dan pada produk Gadai Emas yang menjadi tema judul karya ilmiyah yang akan penulis bahas pada praktiknya, gadai emas belakangan ini marak diselenggarakan oleh perbankan syari'ah, karena dinilai sebagai sarana 
investasi yang menjanjikan. Jika kita amati dengan seksama dalam gadai emas ini terdapat akad rangkap (uqud murakkabah/ multi akad) yaitu gabungan akad rahn dan ijarah, yang mana akad tersebut hanyalah akad pelengkap dari pembiayaan syari'ah, akan tetapi pada saat ini seolah-olah produk gadai emas menjadi produk primadona pada perbankan syari'ah yang menggeser kedudukan produk utama (wadi'ah, mudharabah dan murabahah, dan lain-lain).

Berangkat dari fenomena maraknya pegadaian syari'ah, gadai emas khususnya belakangan ini, penulis tertarik untuk membahas lebih jauh tentang praktik akad pembiayaan gadai emas pada BMT-UGT Sidogiri Cabang Pembantu Kwanyar Bangkalan yang menawarkan berbagai kemudahan antara lain : menerima gadai emas bentuk perhiasan dan lantakan dari ukuran 16 karat sampai 24 karat, nilai taksiran tinggi, nilai pinjaman $90 \mathrm{~s} / \mathrm{d} 93 \%$, Syarat mudah dan proses cepat, biaya sewa tempat dan tempo yang terjangkau sebagai topik bahasan pada penulisan ini.

Dalam penelitian ini agar lebih mudah dan mendalam serta mengena pada sasaran yang dimaksud, maka penulis merumuskan persoalanpersoalan yang diangkat yaitu: tentang praktik akad pembiayaan gadai emas dan tinjauan Hukum Islam terhadap praktik akad pembiayaan gadai emas di BMT-UGT Sidogiri Cabang Pembantu Kwanyar Bangkalan?

Secara Teoritis penelitian ini diharapkan mampu memberikan kontribusi pemikiran bagi khazanah ilmu pengetahuan yang erat kaitannya dengan praktik akad pembiayaan gadai emas pada bank-bank yang menggunakan label syari'ah. Sedangkan secara praktis penelitian ini dapat menjadi sumbangsih kepada praktisi perbankan khususnya bank yang menggunakan sistem syari'ah tentang mekanisme akad pembiayaan gadai emas syari'ah.

\section{B. Metode Penelitian}

Jenis penelitian yang akan digunakan dalam penelitian ini adalah jenis penelitian lapangan (field research) yang bersifat kualitatif yang mana 


\section{Praktif Akad Pembiayan Gadai Emas}

penelitiannya akan menghasilkan data deskriptif berupa kata-kata tertulis atau lisan dari penelitian yang penulis amati. Menjelaskan realitas yang ada dalam menganalisis terhadap praktik akad pembiayaan gadai emas di BMTUGT Sidogiri Cabang Pembantu Kwanyar Bangkalan Perspektif Hukum Islam. Disamping itu penulis juga menggunakan jenis penelitian kepustakaan (library research) yaitu mencari dan mengumpulkan data dan informasi melalui buku-buku, kitab-kitab, dokumen BMT-UGT Sidogiri Cabang Pembantu Kwanyar Bangkalan, dan tulisan-tulisan ilmiah yang

Penelitian ini dilaksanakan di BMT-UGT Sidogiri Cabang Pembantu Kwanyar Bangkalan (Jl. Ketetang Pasar Kwanyar) Bangkalan.dengan alasan

1. Sejauh penulis ketahui produk gadai emas akhir-akhir ini marak diluncurkan oleh bank-bank syari'ah termasuk BMT-UGT Sidogiri Cabang Pembantu Kwanyar Bangkalan yang menjadi trend masyarakat, bukan hanya untuk mendapatkan pinjaman dengan jaminan melainkan untuk berinvestasi.

2. Lokasi BMT-UGT Sidogiri Cabang Pembantu Kwanyar Bangkalan yang stategis di pusat pembelajaan Pasar Kwanyar yang sangat mendukung sebagai obyek penelitian penulis.

Prosedur pengumpulan data yang digunakan dalam penelitian pertama-tama menggunakan tehnik interview yaitu dengan cara bertanya secara langsung secara lisan kepada pihak yang terkait yaitu pimpinan cabang pembantu, penaksir produk gadai, staf-staf lain dan nasabah produk gadai emas BMT-UGT Sidogiri Cabang Pembantu Kwanyar Bangkalan. Interview ini dilakukan guna memperoleh data yang valid mengenai mekanisme praktik akad pembiayaan gadai emas, keunggulan dan manfaatnya.

Langkah yang kedua adalah tehnik pengumpulan data dengan melihat sumber-sumber dokumen yang ada kaitannya dengan jenis data yang diperlukan. Data dokumen yang dimaksud berupa buku-buku literatur, 
dokumen, arsip, serta slip-slip yang berkaitan dengan akad pembiayaan gadai emas.

Demi untuk memperoleh hasil yang memuaskan dalam penelitian ini maka dalam menganalisis data yang diperoleh dari kajian kepustakaan penulis menggunakan metode deduktif, yaitu mengumpulkan data yang diambil dari teori generalisasi yang bersifat umum, selanjutnya ditemukan kenyataan yang bersifat khusus. Dalam hal ini penulis mengungkapkan dalil tentang gadai yang diambil dari Al-Qur'an kemudian penulis memberikan pengertian tentang isi ayat tersebut serta hal-hal yang penting yang termuat dalam ayat tersebut.

Langkah yang kedua dari analisis data ada;lah deskriptif analisis, yaitu menggambarkan atau melukiskan secara sistematis, faktual dan akurat mengenai faktor-faktor, sifat-sifat dan hubungan antara fenomena yang sedang diteliti. Dalam hal ini penulis ingin mengelaborasi tentang praktik operasional gadai emas yang selama ini dijalankan oleh BMT-UGT Sidogiri Cabang Pembantu Kwanyar Bangkalan yang kemudian dapat diambil gambaran dan kesimpulan dari praktik pembiayaan (gadai emas) tersebut.

\section{Hasil Temuan}

Berdasarkan penelitian diatas, terdapat dua poin pokok temuan yang diperoleh dalam penelitian ini. Pertama, dalam praktiknya gadai emas menggunakan akad rangkap (multil uqud murakkabah) yaitu gabungan akad qardh, rahn dan akad ijarah. Transaksi gadai Emas di BMT-UGT Sidogiri Cabang Pembantu Kwanyar Bangkalan sudah sesuai dengan ketentuan hukum Islam dengan terpenuhinya rukun dan syaratnya. Prinsip yang digunakanpun tidak jauh berbeda dengan prinsip gadai pada umumnya. Mulai dari persyaratan biaya (ongkos) administrasi, biaya pemeliharaan/ penyimpanan, hingga mekanisme penjualan barang gadaian ketika pihak yang menggadaikan tidak dapat melunasi utangnya. 


\section{Praktif Akad Pembiayan Gadai Emas}

Kedua, Dalam pandangan hukum Islam transaksi akad pembiayaan gadai emas pada BMT-UGT Sidogiri Cabang Pembantu masih banyak memiliki kekurangan termasuk pada akad ijarah yang terlampir dalam Surat Gadai Syari'ah (SGS), yang setelah penulis analisis ternyata masih belum sesuai dengan prinsip syari'ah (masih mengandung unsur riba). Seperti halnya dalam penentuan biaya sewa tempat yang dihitung setara dengan 1,25\% dari nilai pinjaman per bulan atau dihitung secara persentase, hal ini berlawanan dengan ketentuan penghitungan biaya sewa tempat yang ditentukan pada gadai syari'ah yakni biaya sewa dihitung berdasarkan ketetapan golongan barang dan taksiran, sehingga selain tidak tercapai tujuan ridha bi ridha, terdapat unsur riba dan tidak menjadi maslahat bagi kedua belah pihak. Transaksi ini juga melanggar ketentuan gadai emas itu sendiri dan transaksi seperti ini dinyatakan haram. Kedua poin pokok temuan tersebut dimaksudkan untuk menjawab rumusan masalah penelitian ini.

\section{Penutup}

Penelitian ini merupakan bagian dari usaha yang dapat menjadi muara bagi pengembangan ilmu pengetahuan dengan pendekatan kualitatif. Atas dasar temuan penelitian di atas, penulis dapat mengagenda dua poin sebagai saran penelitian. Pertama, Kepada BMT-UGT Sidogiri Cabang Pembantu Kwanyar Bangkalan: selaku lembaga keuangan yang menggunakan label syari'ah dan berada dalam naungan Dewan Syari'ah Nasional Majelis Ulama' Indonesia (DSN-MUI) dan Dewan Pengawas Syari'ah (DPS), hendaknya meninjau ulang pada :

a. Lembar Surat Gadai Syari'ah (SGS), hendaknya dibuat dengan ukuran lembar dan tulisan yang lebih besar agar dapat dengan jelas dibaca dan dipahami nasabah dalam bertransaksi.

b. Dalam transaksi gadai hendaknya akad yang tertera di belakang SGS dibacakan kepada nasabah, agar nasabah mengerti dan mengetahui isi akad/ kontrak yang dimaksud sehingga tujuan sahnya akad dan ridha 
bi ridha antara kedua belah pihak dapat tercapai, dan diharapkan lebih diperjelas lagi dalam transparansi/ perincian biaya-biaya yang dibebankan pada nasabah agar terhindar dari unsur riba.

c. Sebagai lembaga perbankan yang menggunakan label syari'ah, hendaknya perlu dikaji secara mendalam terhadap akad yang digunakan dalam setiap transaksi dan disesuaikan dengan prinsip syari'ah yang telah tertuang dalam Al-Qur'an dan Al-Sunnah yakni tidak adanya unsur riba, maysir, gharar, haram dan dhalim. Sehingga masyarakat melepas anggapan yang menyatakan bahwa "bank syari'ah sama saja dengan bank umum".

Kedua, Kepada masyarakat pada umumnya, dalam bertransaksi pada suatu perbankan konvensional maupun syari'ah diharapkan lebih aktif dan responsif terhadap segala ketentuan yang ditentukan oleh pihak perbankan, mengkritisi, memberikan saran bila kurang sesuai atau kurang sepakat pada akad yang digunakan demi kemaslahatan bersama. 


\section{Praktif Akad Pembiayan Gadai Emas \\ Daftar Pustaka}

Al-Qur'an dan Terjemah, Departemen Agama Repoblik Indonesia, Jakarta : Darus Sunnah, 2002.

Al-Asqalani, Ibnu Haja, Bulughul Maram, Surabaya : Nurul Huda, 1997.

Al-Jaziri, Abdurrahman, Al-Figh 'ala Al-Madzahib Al-Arba'ah, Jilid2. Bairut : Dar Al-Fikr, 1996.

Ali, Zainuddin, Hukum Gadai Syari'ah, Jakarta : Sinar Grafika, 2008.

Anshori, Abdul Ghofur, Gadai Syariah di Indonesia, Konsep, Implementasi, dan Institionalisasi, Yogyakarta : Gajah Mada University Press, 2006.

Antonio, M. Syafi'I, Bank Syari'ah, Dari Teori ke Praktek, Jakarta : Gema Insani, 2001.

Anwar, Desi, Kamus Lengkap Bahasa Indonesia, Surabaya, AMELIA, 2003.

Ancarya, Akan dan Produk Bank Syari'ah, Jakarta : PT Raja Grafindo Persada, 2008.

Basyir, Ahmad Azhar, Hukum Islam Tentang Riba, Uang Piutang Gadai, Bandung : Al-Maarif, 1983.

Haroen, Nasrun, Fiqih Muamalah, Jakarta : Gaya Media Pratama, 2000. Cet. Pertama.

Hidayat, Taufiq, Buku Pintar Investasi Syari'ah, Jakarta : Mediakita,2011.

Karim, Adiawarman A. Bank Islam (Analisis Fiqih dan Keuangan) Jakarta : Raja Grafindo Persada, 2010. , Bank Islam, Jakarta : PT. Rajawali Press, 2004.

Moleong, Lexy J, Metode Penelitian Koalitatif, Bandung : Remaja Rosda Karya, 2010.

Nazir, Moh, Metode Penelitian, Jakarta : Gralia Indonesia, 2000.

Salim, Joko, Jagan Investasi Emas Sebelum Baca Buku ini, Jakarta : Visimedia, 2010. 
Kholid

Soemitra, Andri, Bank dan Lembaga Keuangan Syari'ah, Jakarta : Kencana, 2009. Cet. I.

Sudarsono, Heri, Bank dan Lembaga Keuangan Syari'ah (Deskripsi dan Ilustrsi) Yogyakarta: 2008. 